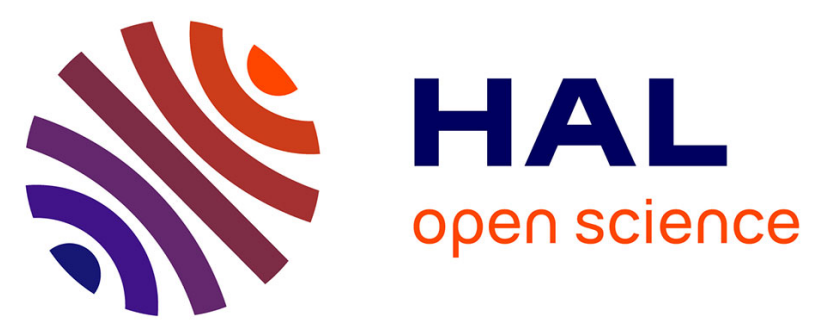

\title{
Chemical processes involving 18-crown-6-ether in activated noncovalent complexes with protonated peptides
}

Marwa Abdelmouleh, Mathieu Lalande, Edith Nicol, Gilles Frison, Guillaume van Der Rest, Jean-Christophe Poully

\section{To cite this version:}

Marwa Abdelmouleh, Mathieu Lalande, Edith Nicol, Gilles Frison, Guillaume van Der Rest, et al.. Chemical processes involving 18-crown-6-ether in activated noncovalent complexes with protonated peptides. ChemPhysChem, 2021, 22 (12), pp.1243-1250. 10.1002/cphc.202100075 . hal-03217252

\section{HAL Id: hal-03217252 \\ https://hal.science/hal-03217252}

Submitted on 4 May 2021

HAL is a multi-disciplinary open access archive for the deposit and dissemination of scientific research documents, whether they are published or not. The documents may come from teaching and research institutions in France or abroad, or from public or private research centers.
L'archive ouverte pluridisciplinaire HAL, est destinée au dépôt et à la diffusion de documents scientifiques de niveau recherche, publiés ou non, émanant des établissements d'enseignement et de recherche français ou étrangers, des laboratoires publics ou privés. 


\title{
Chemical processes involving 18-crown-6-ether in activated noncovalent complexes with protonated peptides
}

\author{
Marwa Abdelmouleh, ${ }^{[a]}$ Mathieu Lalande, ${ }^{[a]}$ Edith Nicol, ${ }^{[b]}$ Gilles Frison, ${ }^{[b, d]}$ Guillaume van der Rest, ${ }^{[c]}$ \\ and Jean-Christophe Poully*[a]
}

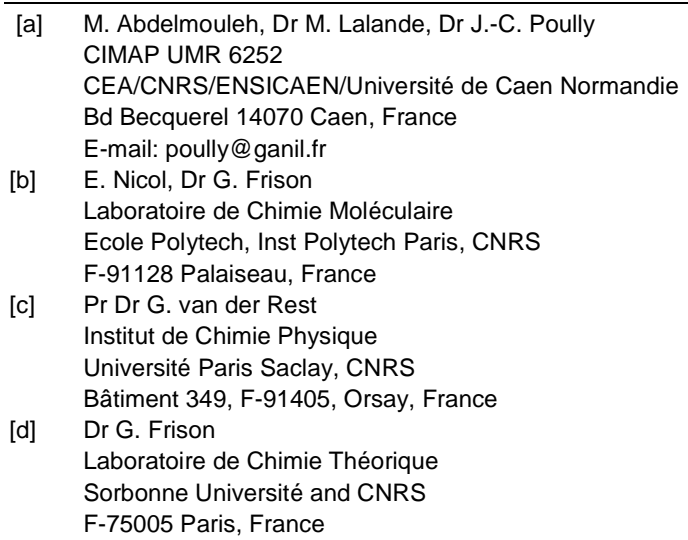

Supporting information for this article is given via a link at the end of the document.

\begin{abstract}
These last decades, it has been widely assumed that 18 crown-6-ether (CE) plays a spectator role during the chemical processes occurring in isolated host-guest complexes between peptides or proteins and CE, after activation in mass spectrometers. Our present experimental and theoretical results challenge this hypothesis by showing that CE can abstract a proton or a protonated molecule from protonated peptides after activation by collisions in argon or electron capture/transfer. Furthermore, thanks to comparison between experimental and calculated values of collision cross-sections, we demonstrate that $\mathrm{CE}$ can change binding site after electron transfer. We also propose detailed mechanisms for these processes.
\end{abstract}

\section{Introduction}

Molecular recognition is a crucial process in many diverse fields, from fundamental supramolecular chemistry of host-guest complexes to biochemistry, from the development of optical chemosensors to the discovery of new drugs. In particular, among other guest molecules, crown ethers have attracted growing interest in the past decades, because of their ability to specifically and noncovalently bind charged chemical groups such as protonated amines and guanidinium, but also atoms such as sodium or potassium. ${ }^{[1]}$ These properties have allowed crown ethers to be especially useful in proteomics, for instance to control the structure and charge state of isolated proteins, ${ }^{[2,3]}$ to probe ionisation mechanisms during the electrospray process ${ }^{[4]}$ or to analyze complex peptide mixtures. ${ }^{[5]}$ In all these studies, it has been assumed that crown ethers bind charged groups and "tag" them. Crown ethers can also be detached after activation of the molecular system during a mass spectrometric analysis of peptides or proteins. Interestingly, activation of protonated proteins bound to several CE was found to induce a charge state reduction, but no explanation was given, ${ }^{[2]}$ Among the most popular techniques is collision-induced dissociation
(CID) or activation, where molecular systems collide with helium argon or nitrogen at kinetic energies usually ranging from $\mathrm{eV}$ to $\mathrm{keV}$. Activation also induces protein unfolding, and ion mobility spectrometry can probe structural dynamics by recording unfolding signatures. ${ }^{[6]}$ CID is the simplest way of inducing peptide or protein backbone cleavage, and has thus been the first technique used to determine their amino-acid sequence by mass spectrometry. However, it suffers from several limitations such as limited sequence coverage or loss of labile posttranslational modifications. These last decades, electron capture and transfer dissociation (ECD, ETD) received increasing attention since they are able to induce backbone cleavage without loss of labile groups or breaking of noncovalent bonds, ${ }^{[7]}$ sometimes even avoiding separation of the two resulting fragments. ${ }^{[8]}$ This peculiarity is accounted for by the formation of a radical ion whose ground-state potential energy barrier for $\mathrm{N}$ $\mathrm{C}_{\alpha}$ bond cleavage is usually very low (below $1 \mathrm{eV}$ ). ${ }^{[9,10]}$ Therefore, the higher-order structures of peptides and proteins can be probed by ECD and ETD. The detailed fragmentation mechanism of these techniques is still debated, and notably the role of proton/ $\mathrm{H}$ transfer from amino groups remains unclear. Thus, a number of groups chose a methodology involving 18crown-6-ethers (CE) to block this process in peptides. ${ }^{[11-14]} \mathrm{CE}$ binding has also recently been used to stabilize intact peptide radical cations after electron transfer and CE evaporation, in order to study their structure and reactivity. ${ }^{[15,16]}$ When these ions undergo $\mathrm{N}-\mathrm{C}_{\alpha}$ bond cleavage, a radical $\mathrm{z}$ fragment ion can be generated, and it has been shown that the position of the radical site can be obtained by UV-visible spectroscopy, the addition of CE making these experiments possible by introducing a mass shift of the photoproduct ions in a spectral region free from pollution. ${ }^{[17]}$

Overall, previous studies have made the hypothesis of a spectator role of $\mathrm{CE}$. This is the case regarding dissociation of noncovalent complexes between CE and peptides or proteins following popular activation techniques in mass spectrometry, especially ECD and ETD. Here, in sharp contrast, we show that 
CE can play an active role when bound to a protonated peptide after activation by collisions on a rare gas or electron capture/transfer: abstracting a proton or a protonated molecule from the peptide, lowering the amount of internal energy, and even changing binding site after ETD. Furthermore, we propose mechanisms for these processes, since clarifying this role in more details is of central importance not only for peptide and proteins analysis by mass spectrometry, but also for supramolecular intrinsic chemistry of host-guest complexes.

\section{Results and Discussion}

\section{Abstraction of a proton}

First, we probe the ability of CE to abstract a proton from the Lysine-Tyrosine-Lysine (KYK) and Lysine-Tryptophan-Lysine (KWK) protonated peptides, and to lower their internal energy after CID and ECD. KYK and KWK were chosen for the following reasons: first, the presence of three highly basic sites where protons can bind (the $\mathrm{N}$-terminus and the two lysine side-chains) allowing for the detection of positive ions after ETD or ECD. Second, lysine is the amino acid with the highest binding affinity for $\mathrm{CE},{ }^{[18]}$ and third, ECD of bare and nanohydrated $[\mathrm{KYK}+2 \mathrm{H}]^{2+}$ has been previously investigated with FT-ICR mass spectrometry. ${ }^{[10]}$ Moreover, fragmentation of complexes between doubly-protonated KYK/KWK and CE after electron transfer from sodium atoms have been studied. ${ }^{[12]}$ Here, we study doubly- and triply-protonated KYK and KWK with one to three CE molecules attached. In our experiments, protonated peptide-CE complexes have been put in the gas phase by means of an electrospray ionisation (ESI) source, selected vs. mass-over-charge $(\mathrm{m} / \mathrm{z})$ ratio with a quadrupole mass filter (QMF), guided to a FT-ICR cell where low-energy electrons have been introduced for 100 ms. CID at low energy in argon has been performed in an octopole following the QMF (see the experimental section for details). Fig. 1 compares the cationic species formed after CID at $5 \mathrm{~V}$ collision voltage and ECD of the triply-protonated noncovalent complex between $\mathrm{KYK}$ and one $\mathrm{CE}$ $[\mathrm{KYK}+3 \mathrm{H}+\mathrm{CE}]^{3+}$ (see Fig. $\mathrm{S} 1$ of the supporting information (SI) for $\left.[\mathrm{KWK}+3 \mathrm{H}+\mathrm{CE}]^{3+}\right)$. Although low-energy CID of nanosolvated charged species usually results in evaporation of neutral solvent molecules, the main channel observed here is loss of protonated CE to form the doubly-protonated KYK or KWK peptide. The latter also undergo $\mathrm{NH}_{3}$ loss, a well-known process in CID of protonated peptides that has been reported to occur from protonated lysine side-chains. ${ }^{[19]}$ Protonated CE at $\mathrm{m} / \mathrm{z}=$ 265.1643 is also detected, as well as one peak at $\mathrm{m} / z=$ 177.1119, which corresponds to $\left[\mathrm{C}_{8} \mathrm{H}_{16} \mathrm{O}_{4}+\mathrm{H}\right]^{+}$and that we assign to a fragment of protonated CE. In the ECD spectrum, the most intense peaks can be assigned to the complementary $\mathrm{b}_{1}{ }^{+} / \mathrm{y}_{2}{ }^{+}$ions formed by amide bond cleavage, $\mathrm{H}$ loss followed by $\mathrm{CE}$ or $\mathrm{NH}_{3}$ losses, $\mathrm{b}_{2}{ }^{+}, \mathrm{C}_{1}{ }^{+}$and also $\mathrm{Z}_{2}{ }^{+}-\mathrm{CO}_{2}$. All these are expected channels after electron capture or transfer, ${ }^{[20]}$ and indeed observed in the bare peptides (cf. Fig. S2). However, a striking difference in the case of $[\mathrm{KYK}+3 \mathrm{H}+\mathrm{CE}]^{3+}$ and $[\mathrm{KWK}+3 \mathrm{H}+\mathrm{CE}]^{3+}$ is the presence of $[\mathrm{CE}+\mathrm{H}]^{+}$together with three fragments: $\left[\mathrm{C}_{8} \mathrm{H}_{16} \mathrm{O}_{4}+\mathrm{H}\right]^{+}$and two other ones at $\mathrm{m} / \mathrm{z}=133.086$ and 89.060, corresponding to $\left[\mathrm{C}_{6} \mathrm{H}_{12} \mathrm{O}_{3}+\mathrm{H}\right]^{+}$and $\left[\mathrm{C}_{4} \mathrm{H}_{8} \mathrm{O}_{2}+\mathrm{H}\right]^{+}$. Such fragments have been reported after CID of the $\mathrm{NH}_{4}{ }^{+}(\mathrm{CE})$ complex and $\mathrm{NH}_{3}$ loss, ${ }^{[21]}$ and are due to successive losses of
$\left(\mathrm{CH}_{2}\right)_{2} \mathrm{O}$ units from protonated $\mathrm{CE}$. We have performed CID of $[\mathrm{CE}+\mathrm{H}]^{+}$that supports this interpretation, since these peaks appear in the mass spectra (see Fig. S1). The presence of fragments of $[\mathrm{CE}+\mathrm{H}]^{+}$in the $\mathrm{ECD}$ spectrum of $[\mathrm{KYK}+3 \mathrm{H}+\mathrm{CE}]^{3+}$ and $[\mathrm{KWK}+3 \mathrm{H}+\mathrm{CE}]^{3+}$ means that $[\mathrm{CE}+\mathrm{H}]^{+}$is vibrationally excited after electron capture and detachment from the peptide. Note that the internal energy transferred to $[\mathrm{CE}+\mathrm{H}]^{+}$and responsible for its fragmentation is lost from the protonated peptide when $[\mathrm{CE}+\mathrm{H}]^{+}$is detached. Therefore, the presence of CE can lower the internal energy of protonated peptides after ECD.

Now, let us discuss the mechanism of formation of $[\mathrm{CE}+\mathrm{H}]^{+}$. If $\mathrm{CE}$ is neutral in the precursor $[\mathrm{KYK}+3 \mathrm{H}+\mathrm{CE}]^{3+}$ ion, proton transfer from KYK has to occur, but it might also be initially protonated. To address this question, we have performed replica-exchange molecular dynamics (REMD) using the AMBER99 force field and density-functional theory (DFT) calculations on the three conformers of $[\mathrm{KYK}+3 \mathrm{H}+\mathrm{CE}]^{3+}$ with $\mathrm{CE}$ bound to each of the three $\mathrm{R}-\mathrm{NH}_{3}{ }^{+}$group (lysine side-chains and $\mathrm{N}$ terminus), and on $[\mathrm{KYK}+2 \mathrm{H}]^{2+}[\mathrm{CE}+\mathrm{H}]^{+}$. REMD explores the ground-state potential energy surface of the system to find the lowest-energy structures, and DFT optimizes their geometry and calculates their relative energy (see the theoretical section for details). We did not find stable species (minima of the groundstate potential energy surface) for $[\mathrm{KYK}+2 \mathrm{H}]^{2+}[\mathrm{CE}+\mathrm{H}]^{+}$with $[\mathrm{CE}+\mathrm{H}]^{+}$bound to $\mathrm{R}-\mathrm{NH}_{2}$ groups: in all cases provided by AMBER99 calculations, the proton is spontaneously transferred back to the nitrogen after DFT optimization. Besides, REMD on $[\mathrm{KYK}+2 \mathrm{H}]^{2+}[\mathrm{CE}+\mathrm{H}]^{+}$led to dissociation of the complex, probably due to Coulomb repulsion. Therefore, finding stable structures including $[\mathrm{CE}+\mathrm{H}]^{+}$not bound to a $\mathrm{R}-\mathrm{NH}_{2}$ group required additional calculations. We had to perform first REMD on $\mathrm{KYK}[\mathrm{CE}+\mathrm{H}]^{+}$and then add two protons on lysine side-chains (they are flexible and can minimize Coulomb repulsion between protons better than when one of them is bound to the $\mathrm{N}$ terminus) of the three lowest-energy conformers, where $[\mathrm{CE}+\mathrm{H}]^{+}$ is not bound to a $\mathrm{R}-\mathrm{NH}_{2}$ group. Their DFT energy is over 180 $\mathrm{kJ} . \mathrm{mol}^{-1}$ higher than the lowest-energy conformers of $[\mathrm{KYK}+3 \mathrm{H}]^{3+}(\mathrm{CE})$ (see Table $\mathrm{S} 1$ of the $\mathrm{SI}$ ), which allows assuming that $\mathrm{CE}$ is neutral in $[\mathrm{KYK}+3 \mathrm{H}+\mathrm{CE}]^{3+}$ before activation. Since the tyrosine side-chain is not involved in CE binding, we assume that these results can be extended to $[\mathrm{KWK}+3 \mathrm{H}+\mathrm{CE}]^{3+}$. Therefore, the presence of $[\mathrm{CE}+\mathrm{H}]^{+}$and its fragments in $\mathrm{CID}$ and ECD spectra means that proton transfer from KYK to CE has occurred. The presence of $[\mathrm{CE}+\mathrm{H}]^{+}$in $\mathrm{ECD}$ spectra of protonated peptides has been very scarcely reported. ${ }^{[14]}$ Note that proton transfer from reduced alkanediammonium cations to dibenzo-18-crown-6-ether after electron capture has been found to occur. ${ }^{[22]}$ 


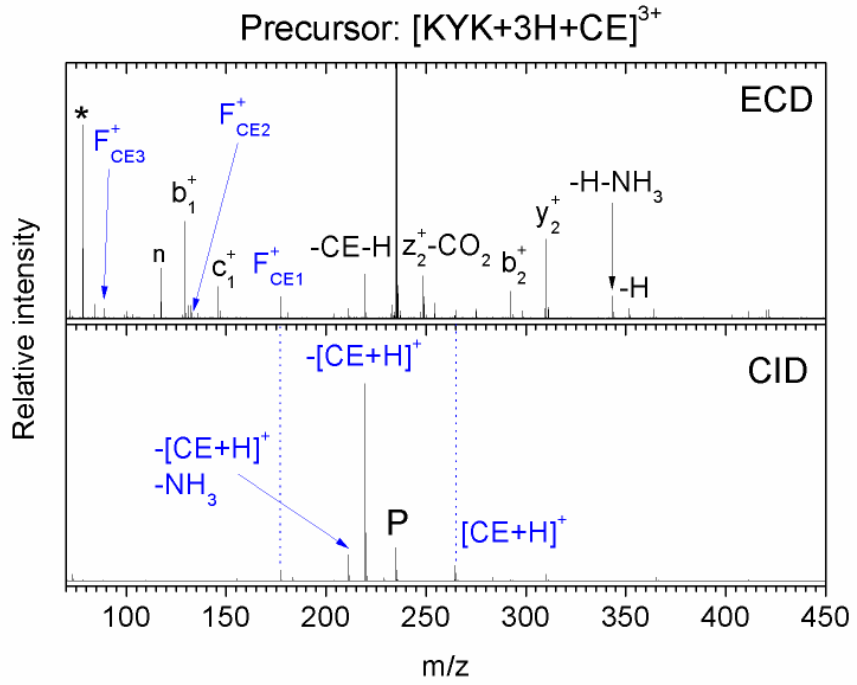

Figure 1. Mass spectra of $[\mathrm{KYK}+3 \mathrm{H}+\mathrm{CE}]^{3+}$ (precursor, noted $\mathrm{P}, \mathrm{m} / \mathrm{z} 234.8$ ) after ECD and CID at $5 \mathrm{~V}$ collision voltage. The second harmonics of the precursor peak is indicated by an asterisk. $\mathrm{n}$ denotes background noise peaks. Fragments of protonated 18-crown-6-ether $\left(\left[\mathrm{C}_{12} \mathrm{H}_{24} \mathrm{O}_{6}+\mathrm{H}\right]^{+}\right.$, noted $\left.[\mathrm{CE}+\mathrm{H}]^{+}\right)$are called $\mathrm{F}^{+}{ }_{\mathrm{CE} 1}, \mathrm{~F}^{+} \mathrm{CE}_{2}$ and $\mathrm{F}^{+} \mathrm{CE} 3$ and correspond to $\left[\mathrm{C}_{8} \mathrm{H}_{16} \mathrm{O}_{4}+\mathrm{H}\right]^{+},\left[\mathrm{C}_{6} \mathrm{H}_{12} \mathrm{O}_{3}+\mathrm{H}\right]^{+}$ and $\left[\mathrm{C}_{4} \mathrm{H}_{8} \mathrm{O}_{2}+\mathrm{H}\right]^{+}$, respectively. They appear in blue, as $[\mathrm{CE}+\mathrm{H}]^{+}$and species involved in loss of $[\mathrm{CE}+\mathrm{H}]^{+}$.

\section{Abstraction of a protonated molecule}

We have shown that CE can abstract a proton from protonated peptides as a result of collisional activation or electron capture, via protonated CE loss. The next questions are: is it the only channel leading to positive charge removal, and does it occur after electron transfer from a molecular anion? To address them, we have performed experiments where protonated peptides-CE complexes have interacted with fluoranthene anions during 20 and $60 \mathrm{~ms}$ in an octopole for triply- and doubly-charged precursor ions, respectively, and product cations have been analyzed by FT-ICR mass spectrometry (see the experimental section for details). Fig. 2 shows the ECD and ETD mass spectra of $[\mathrm{KYK}+3 \mathrm{H}+2 \mathrm{CE}]^{3+}$ and $[\mathrm{KYK}+2 \mathrm{H}+\mathrm{CE}]^{2+}$. The same spectra are shown in Fig. S5 for KWK. After ECD, all product ions come from loss of $\mathrm{CE}$ and fragmentation of the peptide $(\mathrm{H}$ and/or $\mathrm{NH}_{3}$ or $\mathrm{H}_{2} \mathrm{O}$ losses; $\mathrm{N}-\mathrm{C}_{\alpha}$ bond cleavage; only for $\mathrm{KWK}$ : loss of $\mathrm{CE}$ and tryptophan side-chain, formation of an internal fragment), as expected, except one: $\mathrm{NH}_{4}{ }^{+}(\mathrm{CE})$. Interestingly, the formation of $\mathrm{NH}_{4}{ }^{+}$has never been reported for protonated peptides after electron capture or transfer, as far as we know, pointing to a role of CE. We attribute the formation of $\mathrm{NH}_{4}^{+}(\mathrm{CE})$ to electron capture in the $\sigma^{*}$ orbital of the $\mathrm{C}-\mathrm{N}$ bond belonging to a $\mathrm{R}-\mathrm{NH}_{3}{ }^{+}(\mathrm{CE})$ group, followed by cleavage of this bond, formation of $\mathrm{NH}_{3}(\mathrm{CE})$ and finally proton transfer to $\mathrm{N}$. This proton transfer is favored by the presence of CE that increases proton affinity compared to the bare $\mathrm{NH}_{3}$. Moreover, DFT calculations have highlighted the role of $\mathrm{H}$-bonding on the electron capture to

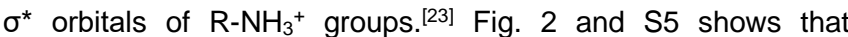
electron transfer from fluoranthene anions to $[\mathrm{KYK}+3 \mathrm{H}+2 \mathrm{CE}]^{3+}$, $[\mathrm{KYK}+2 \mathrm{H}+\mathrm{CE}]^{2+}$ and the corresponding $\mathrm{KWK}$ complexes also leads to the formation of $\mathrm{NH}_{4}{ }^{+}(\mathrm{CE})$, and the other product ions are due to the same peptide fragmentation channels as ECD, but without CE evaporation. It is consistent with the fact that a lower amount of vibrational energy is transferred to the molecular system after electron transfer vs. capture, as already reported. ${ }^{[8]}$ This energy cannot exceed the electron recombination energy, which has been measured to be $4.3 \mathrm{eV}$ for electron capture by $[\mathrm{KYK}+2 \mathrm{H}]^{2+}$ and around $3 \mathrm{eV}$ for electron transfer to doubly-charged peptides. ${ }^{[10,24]}$ Besides, the recombination energy after electron capture by a triply-charged nanosolvated ion has been measured to be around $9 \mathrm{eV}$ by nanocalorimetry. ${ }^{[25]}$ This allows overcoming the energy barrier for $\mathrm{C}_{-} \mathrm{NH}_{3}{ }^{+}$bond cleavage (about $0.4 \mathrm{eV}$ ) after electron capture, ${ }^{[26]}$ and the proton transfer barrier, which has been calculated to be $0.6-0.8 \mathrm{eV}$ in the doubly-protonated TIK peptide. ${ }^{[27]}$
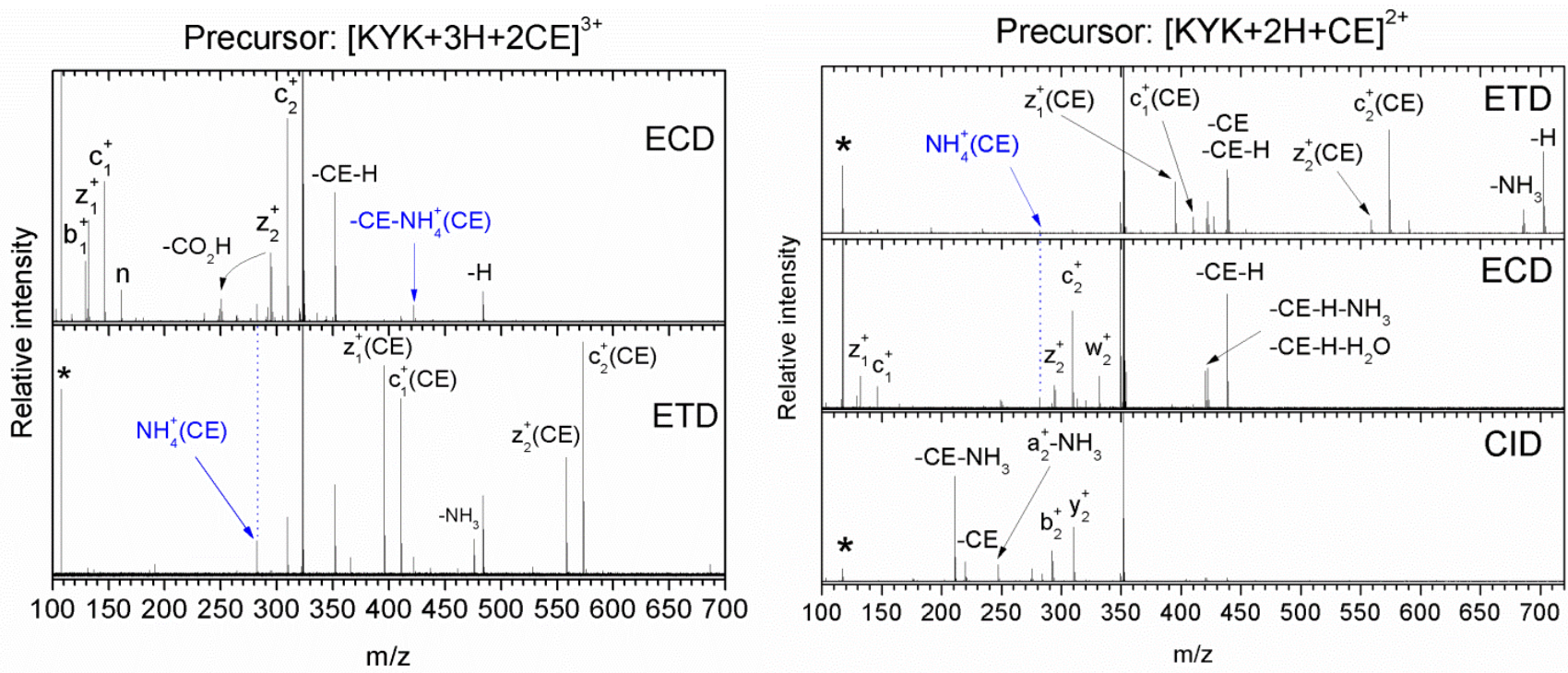

Figure 2. Mass spectra of $[\mathrm{KYK}+3 \mathrm{H}+2 \mathrm{CE}]^{3+}$ (left, $\mathrm{m} / z$ 322.9) and $[\mathrm{KYK}+2 \mathrm{H}+\mathrm{CE}]^{2+}$ (right, $\mathrm{m} / z$ 351.7) after ETD, ECD and $\mathrm{CID}$ at $15 \mathrm{~V}$ collision voltage. The second harmonics of the precursor peak is indicated by an asterisk. $n$ denotes background noise peaks. The peaks assigned to $\mathrm{NH}_{4}{ }^{+}(\mathrm{CE})$ and loss of this ion are highlighted in blue. 
More information is obtained by probing the structure of KYK/KWK-CE complexes. We have performed traveling wave ion mobility spectrometry (TWIMS) experiments on $[\mathrm{KYK}+2 \mathrm{H}+\mathrm{CE}]^{2+}$ and $[\mathrm{KWK}+2 \mathrm{H}+\mathrm{CE}]^{2+}$ ions produced by an ESI source, selected by a QMF with respect to $\mathrm{m} / \mathrm{z}$ ratio, and accumulated in an ion trap, where dicyanobenzene anions can be injected to perform ETD. Then, the product cations are guided to a traveling wave cell filled with a nitrogen gas where structural conformers with different collision cross-sections (CCS) are separated in space and time. The arrival time distribution (ATD) of all ions is recorded and their $\mathrm{m} / \mathrm{z}$ is analyzed by a time-of-flight mass spectrometer. Thanks to a calibration procedure, a CCS value has been assigned to each peak in the ATD. The latter are shown in Fig. S3 and S4, and the corresponding measured collision cross-sections (CCS) in nitrogen are gathered in Table 1, along with uncertainties. All details can be found in the experimental section. In the same table, we compare those experimental values to the results of simulations carried out thanks to the IMOS software, ${ }^{[28]}$ for different protonation as well as CE binding sites. The probability for the two protons to be located at the $\mathrm{N}$ terminus and $\mathrm{N}$ terminal lysine side-chain is too low to be considered in $[\mathrm{KYK}+2 \mathrm{H}+\mathrm{CE}]^{2+}$ and $[\mathrm{KWK}+2 \mathrm{H}+\mathrm{CE}]^{2+}$, because of the high Coulomb repulsion compared to the case of protons at the two lysine side-chains. This is supported by DFT and MP2 calculations of the potential energy of $[\mathrm{KWK}+2 \mathrm{H}]^{2+}$ : with the protons at the $\mathrm{N}$ terminus and $\mathrm{N}$-terminal lysine side-chain, the system is more than $80 \mathrm{~kJ} / \mathrm{mol}$ higher in energy than the conformer having both protons at lysine side-chains. ${ }^{[12]}$ To generate the structure of each complex, a conformational search has been performed with REMD, and the conformer of lowestenergy optimized structure has been selected (see the theoretical section for details and Fig. 3 for pictures of all conformers for $\mathrm{KYK})$. The calculated CCS values of the $[\mathrm{KYK}+2 \mathrm{H}+\mathrm{CE}]^{2+}$ and $[\mathrm{KWK}+2 \mathrm{H}+\mathrm{CE}]^{2+}$ conformers with $\mathrm{CE}$ bound to the $\mathrm{C}$-terminal lysine side-chain agree well with the experimental values, but when CE binds to another protonated site, it is clearly off. Moreover, the conformer with CE bound to the C-terminal lysine side-chain and with the two protons at lysine side-chains has the lowest DFT potential energy. Therefore, regarding $\mathrm{NH}_{4}{ }^{+}(\mathrm{CE})$ formation after ETD, the electron is most probably transferred to the C-terminal lysine side-chain and the proton comes either from the other lysine side-chain, or from the carboxyl group. However, the latter is less likely, since the gas-phase proton affinity of amines is lower than that of carboxylates, and it would result in a zwitterion, which has been shown to be stable in the gas phase only in the presence of a salt-bridge. ${ }^{[29,30]}$ It is interesting to notice that the need for proton transfer from the protonated lysine side-chain and not the carboxyl group is supported by the absence of $\mathrm{NH}_{4}{ }^{+}(\mathrm{CE})$ after electron capture or transfer to $[\mathrm{KYK}+2 \mathrm{H}+2 \mathrm{CE}]^{2+}$ or $[\mathrm{KWK}+2 \mathrm{H}+2 \mathrm{CE}]^{2+}$ (cf. Fig. $\mathrm{S} 6$ and $\mathrm{S} 7$ ), in which the remaining proton is $\mathrm{H}$-bound to $\mathrm{CE}$ and thus much less mobile, as earlier work has shown. ${ }^{[31]}$

Table 1. Theoretical and experimental cross-sections (CCS) for collision between a nitrogen gas and different conformers of $[\mathrm{KYK}+2 \mathrm{H}+\mathrm{CE}]^{2+}$, $[\mathrm{KWK}+2 \mathrm{H}+\mathrm{CE}]^{2+}$ and their respective $\mathrm{C}_{2}{ }^{+}(\mathrm{CE})$ fragments, as well as relative ground-state potential energy of $[\mathrm{KYK}+2 \mathrm{H}+\mathrm{CE}]^{2+}$. $[\mathrm{KWK}+2 \mathrm{H}+\mathrm{CE}]^{2+},[\mathrm{KYK}+3 \mathrm{H}+2 \mathrm{CE}]^{3+},[\mathrm{KWK}+3 \mathrm{H}+2 \mathrm{CE}]^{3+}$ and the $\mathrm{C}_{2}{ }^{+}(\mathrm{CE})$ fragments calculated at $0 \mathrm{~K}$ at the DFT level (M06 functional, basis set indicated, based on AMBER99 geometries). The lowest-energy conformers are highlighted in bold.

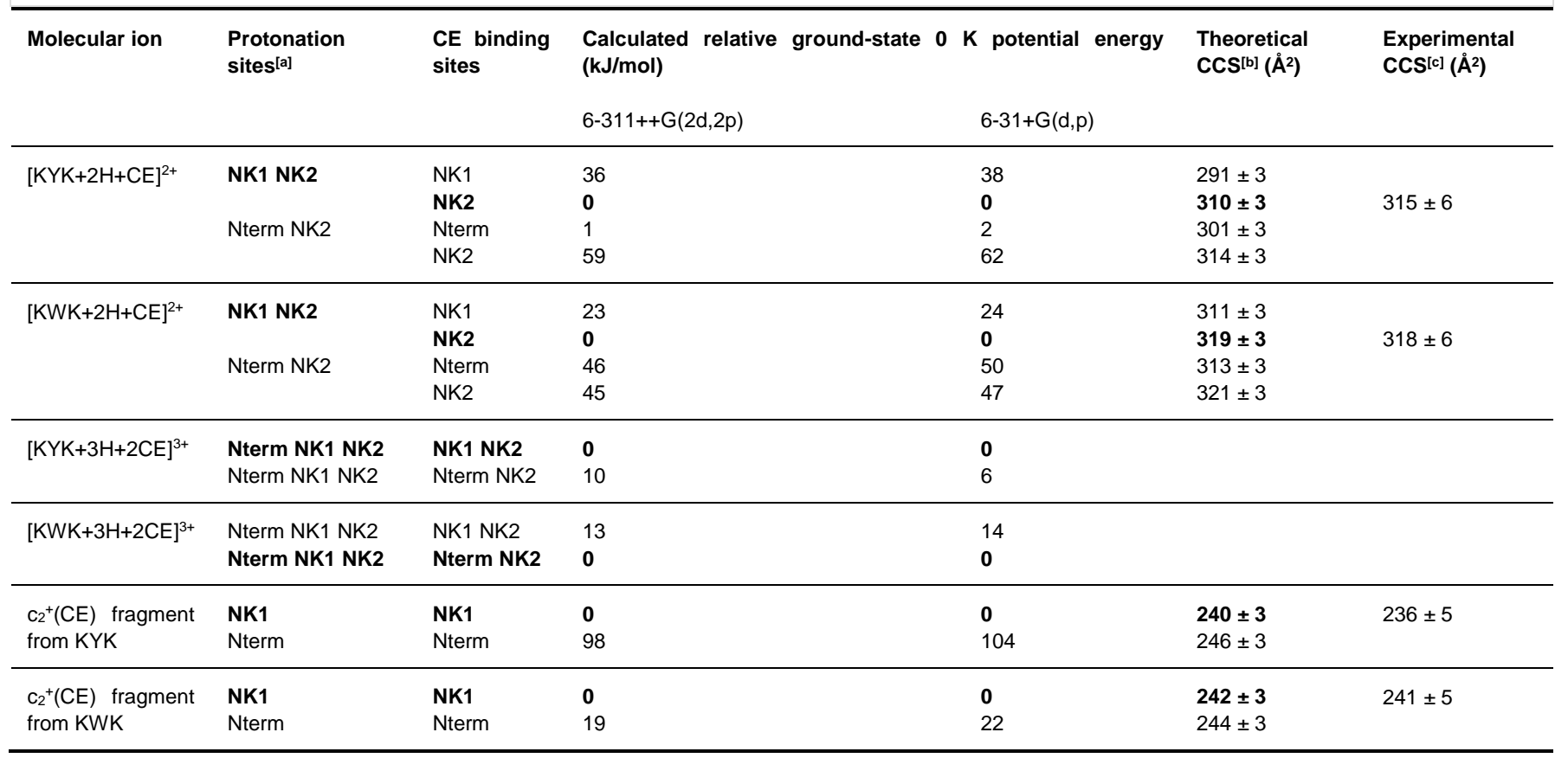

[a] Nterm, NK1 and NK2 stand for N terminus, N-terminal and C-terminal lysine side-chains, respectively. [b] Calculations made with the IMOS software, ${ }^{[28]}$ see the SI for details. [c] Values corresponding to the maximum of the peaks observed in the arrival time distribution, see the SI for details. 


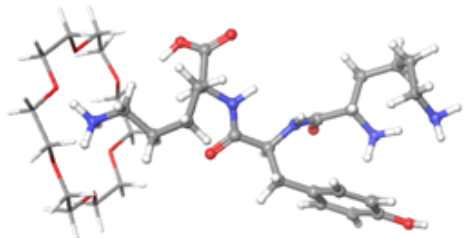

Protons: NtermNK2 ; CE: NK2 $E=59 \mathrm{~kJ} / \mathrm{mol}$

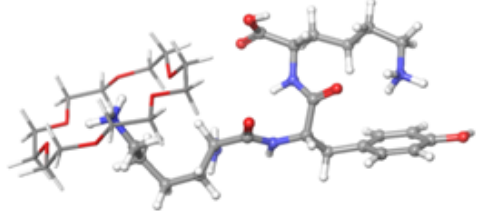

Protons: NK1NK2; CE: NK1; $E=36 \mathrm{~kJ} / \mathrm{mol}$

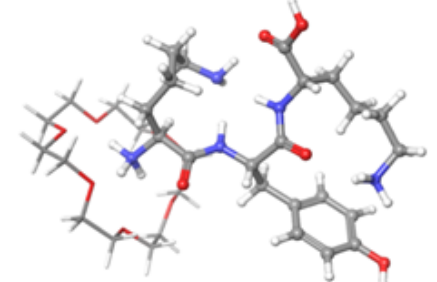

Protons: NtermNK2 CE: Nterm ; $E=1 \mathrm{~kJ} / \mathrm{mol}$

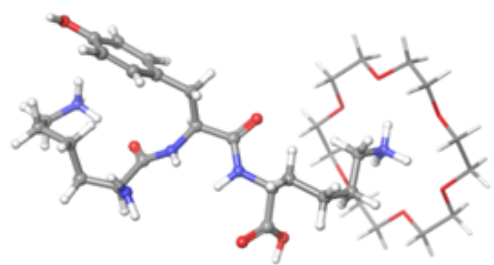

Protons: NK1NK2 ; CE: NK2 ; $E=0 \mathrm{~kJ} / \mathrm{mol}$

$[\mathrm{KYK}+\mathbf{2 H}+\mathrm{CE}]^{2+}$

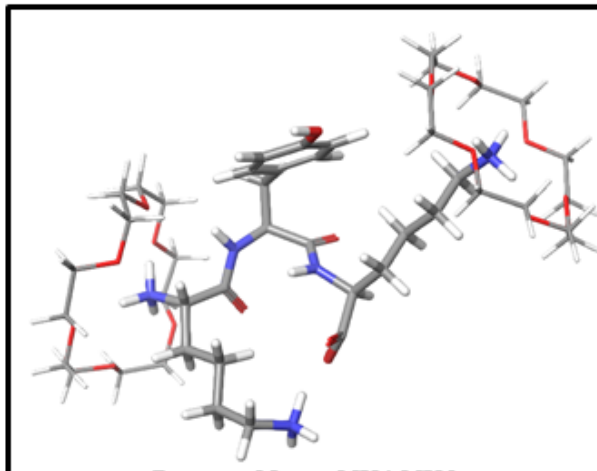

Protons: Nterm NK1 NK2

CE: Nterm NK2

$E=10 \mathrm{~kJ} / \mathrm{mol}$

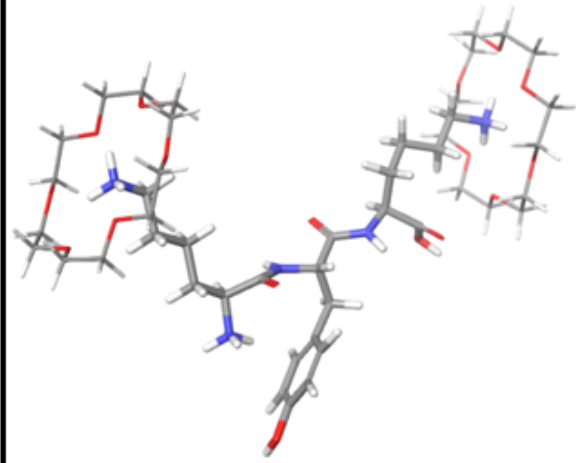

Protons: Nterm NK1 NK2

CE: NK1 NK2

$E=0 \mathrm{~kJ} / \mathrm{mol}$

$[\mathrm{KYK}+3 \mathrm{H}+2 \mathrm{CE}]^{3+}$

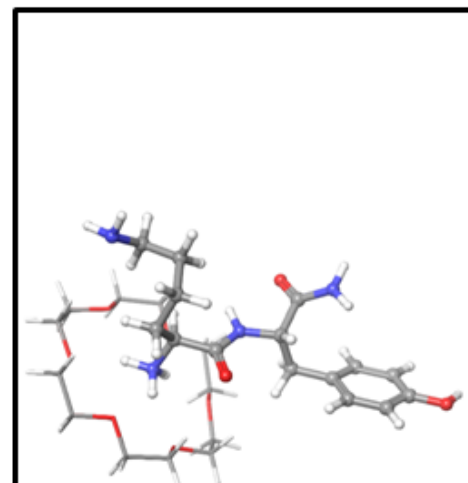

Proton: Nterm ; CE: Nterm $E=98 \mathrm{~kJ} / \mathrm{mol}$

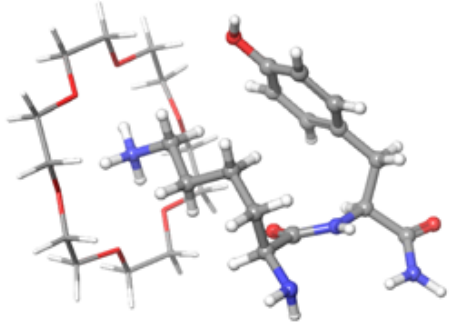

Proton: NKl ; CE: NKl $E=0 \mathrm{~kJ} / \mathrm{mol}$

\section{$c_{2}^{+}(C E)$ fragment}

Figure 3. Structure and energy of the lowest-energy conformers found after replica-exchange molecular dynamics simulations and DFT calculations (see Table 1 and the theoretical section for details) of $[\mathrm{KYK}+2 \mathrm{H}+\mathrm{CE}]^{2+}$, $[\mathrm{KYK}+3 \mathrm{H}+2 \mathrm{CE}]^{3+}$ and the $\mathrm{C}_{2}{ }^{+}(\mathrm{CE})$ fragment. $\mathrm{CE}$ is depicted in thin tubes and $\mathrm{KYK}$ in balls and sticks. $\mathrm{H}$, $\mathrm{C}, \mathrm{N}$ and $\mathrm{O}$ atoms are depicted in white, grey, blue and red, respectively.

After ECD and ETD of $[\mathrm{KYK}+3 \mathrm{H}+2 \mathrm{CE}]^{3+}$ and $[\mathrm{KWK}+3 \mathrm{H}+2 \mathrm{CE}]^{3+}$, $\mathrm{NH}_{4}{ }^{+}(\mathrm{CE})$ formation is accompanied by its complementary singly-charged fragment with loss of CE (see Fig. 2 and S5). This is expected, since the system is doubly-charged after single electron capture or transfer. Besides, our calculations reveal that among the three protonated sites of $[\mathrm{KYK}+3 \mathrm{H}+2 \mathrm{CE}]^{3+}$, the $\mathrm{N}-$ terminus and the two lysine side-chains, the latter are also bound to the two CE (see Table 1 and Fig. 3). Moreover, the free proton is close to the $\mathrm{N}$-terminal lysine, the following mechanism can thus be inferred: electron capture/transfer to the $\mathrm{N}$-terminal lysine followed by creation of $\mathrm{NH}_{3}(\mathrm{CE})$, which then abstracts a proton from the $\mathrm{N}$ terminus. The situation is a bit different for $[\mathrm{KWK}+3 \mathrm{H}+2 \mathrm{CE}]^{3+}$, since the conformer with $\mathrm{CEs}$ at the $\mathrm{N}$ terminus and $\mathrm{C}$-terminal lysine is predicted to be the lowest-energy one. Thus, electron capture/transfer would occur to the $\mathrm{N}$ terminus and abstraction of a proton from the $\mathrm{N}$-terminal lysine. In both cases, the $\mathrm{NH}_{4}^{+}(\mathrm{CE})$ formation process involves only the $\mathrm{N}$-terminal part of the tripeptides. Interestingly, the formation of $\mathrm{NH}_{4}{ }^{+}(\mathrm{CE})$ is also observed for $[\mathrm{KYK}+3 \mathrm{H}+3 \mathrm{CE}]^{3+}$ and $[\mathrm{KWK}+3 \mathrm{H}+3 \mathrm{CE}]^{3+}$ (see Fig. S6 and $\mathrm{S} 7$ ), where each proton is bound to a $\mathrm{CE}$, like in $[\mathrm{KYK}+2 \mathrm{H}+2 \mathrm{CE}]^{2+}$ and $[\mathrm{KWK}+2 \mathrm{H}+2 \mathrm{CE}]^{2+}$. It might be due to an increase of $\mathrm{CE}$ evaporation due to the much higher recombination energy after electron capture by a triply-charged nanosolvated ion, which has been measured to be around $9 \mathrm{eV}$ by nanocalorimetry. ${ }^{[25]}$ Furthermore, another peak is visible at $\mathrm{m} / \mathrm{z} 336.237$ in the ECD spectrum of $[\mathrm{KYK}+3 \mathrm{H}+3 \mathrm{CE}]^{3+}$ and $[\mathrm{KWK}+3 \mathrm{H}+3 \mathrm{CE}]^{3+}$ : we assign it to the protonated lysine side-chain bound to $\mathrm{CE}\left(\mathrm{KSC}^{+}(\mathrm{CE})\right)$. As for loss of $\mathrm{NH}_{4}{ }^{+}$, we are aware of no report on loss of protonated lysine side-chain from protonated peptides. For complexes between CE and peptides containing protonated arginine or/and histidine side-chains, where the charge is more delocalized, only formation of $[\mathrm{CE}+\mathrm{H}]^{+}$upon ECD has been reported. ${ }^{[14]}$ It may be due to the much lower binding energy of $C E$ to these side-chains compared to lysine ${ }^{[18]}$ favoring CE loss after electron capture. Another reason might be the different behavior of peptides containing protonated arginine and histidine upon electron capture. However, it seems to be less likely, since lysine, histidine and arginine side-chain losses have been reported. ${ }^{[32]}$.

\section{CE motion after electron transfer}

In the previous sub-sections, positive charge removal from protonated peptides by loss of $[\mathrm{CE}+\mathrm{H}]^{+}, \mathrm{NH}_{4}{ }^{+}(\mathrm{CE})$ and $\mathrm{KSC}^{+}(\mathrm{CE})$ 
is demonstrated. Now, let us discuss the case of CE transfer within $[\mathrm{KYK}+2 \mathrm{H}+\mathrm{CE}]^{2+}$ and $[\mathrm{KWK}+2 \mathrm{H}+\mathrm{CE}]^{2+}$ after electron transfer. Initially, $\mathrm{CE}$ is bound to the $\mathrm{C}$-terminal protonated lysine side-chain (see the previous sub-sections and Fig. 3), and electron transfer leads to abundant $\mathrm{C}_{2}{ }^{+}(\mathrm{CE})$ and $\mathrm{z}_{1}{ }^{+}(\mathrm{CE})$ fragment ions as well as weaker $\mathrm{C}_{1}{ }^{+}(\mathrm{CE})$ and $\mathrm{z}_{2}{ }^{+}(\mathrm{CE})$ (see Fig. 2 and $\mathrm{S} 5$ ). While $\mathrm{z}_{1}{ }^{+}(\mathrm{CE})$ and $\mathrm{z}_{2}{ }^{+}(\mathrm{CE})$ can be readily explained by $\mathrm{N}-\mathrm{C}_{\alpha}$ bond cleavage without $\mathrm{CE}$ loss from the C-terminal protonated lysine side-chain, the presence of $\mathrm{C}_{1}{ }^{+}(\mathrm{CE})$ and $\mathrm{C}_{2}{ }^{+}(\mathrm{CE})$ is unexpected, because $\mathrm{N}-\mathrm{C}_{\alpha}$ bond cleavage in the conformer shown in Fig. 3 should lead to the bare $\mathrm{C}_{1}{ }^{+}$and $\mathrm{C}_{2}{ }^{+}$ fragments. Thus, the presence of CE on these fragments implies $\mathrm{CE}$ transfer from the C-terminal protonated lysine side-chain to the N-terminal side of the peptide. Schalley and co-workers ${ }^{[33]}$ have shown, thanks to $H / D$ exchange mass spectrometry, that CE moves with one proton from a $\mathrm{R}-\mathrm{NH}_{3}{ }^{+}$site to an adjacent $\mathrm{R}$ $\mathrm{NH}_{2}$ site in oligolysine peptides ${ }^{[33]}$ as well as polyaminopropylene amine dendrimers ${ }^{[34]}$. Moreover, in $[\mathrm{KYK}+2 \mathrm{H}+\mathrm{CE}]^{2+}$ and $[\mathrm{KWK}+2 \mathrm{H}+\mathrm{CE}]^{2+}$, the protonated $\mathrm{N}$ terminal lysine side-chain is expected to be the main electron transfer site because its recombination energy is higher than the CE-bound one. ${ }^{[9]}$ Besides, its $\mathrm{R}-\mathrm{NH}_{3}{ }^{+}$group is $\mathrm{H}$-bound to the $\mathrm{C}=\mathrm{O}$ of the first amide bond, and $\mathrm{H}$ transfer to amide groups has been found to induce low-barrier formation of $\mathrm{c}$ and $\mathrm{z}$ ions after electron capture or transfer. ${ }^{[35]}$ Therefore, here we propose that electron transfer occurs at the $\mathrm{N}$-terminal lysine side-chain of $[\mathrm{KYK}+2 \mathrm{H}+\mathrm{CE}]^{2+}$ or $[\mathrm{KWK}+2 \mathrm{H}+\mathrm{CE}]^{2+}$, triggers $\mathrm{H}$ transfer, subsequent $\mathrm{N}-\mathrm{C}_{\alpha}$ bond cleavage, and transfer of $[\mathrm{CE}+\mathrm{H}]^{+}$to an $\mathrm{R}-\mathrm{NH}_{2}$ site. But there are two in the formed $\mathrm{C}_{2}{ }^{+}(\mathrm{CE})$ ion: the $\mathrm{N}$ terminus and the lysine side-chain. We can find the binding site of CE from ion mobility measurements and calculations (cf. Fig. S4 and Table 1). The lowest-energy $\mathrm{C}_{2}{ }^{+}(\mathrm{CE})$ conformers, for which CE is bound to the $\mathrm{N}$-terminal lysine side-chain (cf. Fig. 3 for $\mathrm{KYK}$ ), has the closest calculated CCS compared to the experimental one, and the potential energy of the other $\mathrm{C}_{2}{ }^{+}(\mathrm{CE})$ conformers (with $\mathrm{CE}$ bound to the protonated $\mathrm{N}$ terminus, see Fig. 3) is significant for KWK (about $20 \mathrm{~kJ}^{\mathrm{mol}}{ }^{-1}$ ) and very high for KYK (about $100 \mathrm{~kJ}^{\mathrm{mol}}{ }^{-1}$ ). Thus, upon electron transfer to the $\mathrm{N}$-terminal lysine side-chain, $[\mathrm{CE}+\mathrm{H}]^{+}$moves from the $\mathrm{C}$-terminal to the $\mathrm{N}$-terminal lysine side-chains of the peptide. Therefore, our results show that the presence of tyrosine or tryptophan in between lysines does not inhibit CE motion, and the energy needed for this process cannot be higher than the recombination energy of the transferred electron (about $3 \mathrm{eV}$ ). ${ }^{[10,24]}$

\section{Conclusion}

In this work, we apply mass and ion mobility spectrometry techniques to study the influence of noncovalent binding of 18 crown-6-ether, a widely-used charge-tagging molecule, on the electron-induced processes in protonated tripeptides. We give evidence that this molecule is not always acting as a spectator, contrary to previously assumed, since it can take away a proton but also protonated molecules coming from lysine side-chains, lower the internal energy of the peptide, and can even "jump over" one tyrosine or tryptophan residue as a result of electron transfer. Given the numerous applications of the electron-based dissociation techniques for the mass spectrometric analysis of peptides and proteins, and the increasing use of crown-ethers in mass spectrometry, such processes have to be considered in data analysis of these studies. Overall, our results provide an explanation to the previously reported charge state reduction after CID of protonated proteins bound to several CE, ${ }^{[2]}$ and interestingly, they also suggest that even lower protein charge states may be reached by means of ECD or ETD of these noncovalent complexes. 


\section{Experimental and Theoretical Section}

Powders of lysine-tyrosine-lysine (KYK; $>90 \%$ purity), lysine-tryptophanlysine (KWK; >90\% purity), and 18-crown-6-ether (CE; >99\% purity) have been purchased from Proteogenix (peptides) and Sigma-Aldrich, respectively, and used without further purification. Protonated molecular systems have been put in the gas phase by electrospray ionisation (ESI) from a water/methanol solution (50\%/50\% in volume) with $1 \%$ acetic acid Concentrations were about $10 \mu \mathrm{M}$ for $\mathrm{KYK}$ and $30 \mu \mathrm{M}$ for $\mathrm{CE}$.

All collision-induced, electron-capture and electron-transfer dissociation (CID, ECD and ETD) mass spectra presented in the manuscript have been acquired using a commercial mass spectrometer FT-ICR SolarixXR 9.4T (Bruker Daltonics, Bremen, Germany) located at Laboratoire de Chimie Moléculaire (Ecole Polytechnique, Palaiseau, France). The ESI source is followed by ions funnels and hexapôle for focusing and guiding the ions to a quadrupole mass filter (QMF) for mass-over-charge $(\mathrm{m} / \mathrm{z})$ selection of the molecular ions of interest. Then, they are accumulated in an octopole, where fluoranthene anions are injected during 60 or $20 \mathrm{~ms}$ to perform ETD on doubly- and triply-charged species, respectively, and argon gas is injected for CID. An octopole allows guiding the product ions to an FT-ICR Paracell ${ }^{\mathrm{TM}}$, where $\mathrm{m} / \mathrm{z}$ analysis is performed with a typical resolution power of $3 \times 10^{5}$. Low-energy electrons are injected in the cell during $100 \mathrm{~ms}$ for $\mathrm{ECD}$. For $\mathrm{CID}$ of isolated $[\mathrm{KWK}+3 \mathrm{H}+\mathrm{CE}]^{3+}$, sustained off-resonance irradiation (SORI) in the FT-ICR cell has been applied at $0.5 \%$ of SORI power with $0.2 \mathrm{~s}$ of pulse length and $1000 \mathrm{~Hz}$ for the frequency offset.

Ion-mobility spectrometry experiments have been performed using a commercial set-up (Synapt G2-Si, Waters Company, Manchester, UK) that has been described elsewhere. ${ }^{[36]}$ Briefly, a Z-Spray ESI source is followed by a StepWave travelling wave system, a selection quadrupole mass filter, then a TriWave cell, consisting in four successive travelling wave sectors with varying gases (Ar in the Trap cell, He in the helium cell, nitrogen in the IMS cell and Ar in the Transfer cell) and a time-of-flight mass spectrometer for $\mathrm{m} / \mathrm{z}$ and arrival time distribution measurements. $\mathrm{m} / \mathrm{z}$ calibration has been performed using sodium trifluoroacetate, the typical standard error being below $5 \mathrm{ppm}$. The following instrumental parameters were used: capillary voltage $=3.0 \mathrm{kV}$, sampling cone $=40 \mathrm{~V}$, source offset $=80 \mathrm{~V}$, nebulization gas pressure $=6.5 \mathrm{bar}$, source temperature, $80{ }^{\circ} \mathrm{C}$, desolvation temperature, $280{ }^{\circ} \mathrm{C}$, desolvation gas flow $=650 \mathrm{~L} / \mathrm{h}$, cone gas flow $=0$. For ion mobility (IMS) experiments in nitrogen as drift gas, the following instrumental parameters were used: Trap gas flow $=7 \mathrm{ml} / \mathrm{min}$; He gas flow $=120 \mathrm{ml} / \mathrm{min}$, IMS gas flow $=45$ $\mathrm{ml} / \mathrm{min}$, Trap wave velocity $=300 \mathrm{~m} / \mathrm{s}$, Trap wave height $=5 \mathrm{~V}$, IMS wave velocity $=800 \mathrm{~m} / \mathrm{s}$, IMS wave height $=40 \mathrm{~V}$, Transfer wave velocity $=110$ $\mathrm{m} / \mathrm{s}$ and Transfer wave height $=4 \mathrm{~V}$. ETD experiments were performed by trapping the mass filtered ions in the ion trap and injecting dicyanobenzene $(m / z 128)$ anions produced by a discharge source included in the ion source block. A CCS calibration has been done for each charge state $(1+, 2+$ and $3+)$ thanks to IMS measurements of protonated polyalanine peptides with a wide distribution of size. Uncertainties have been estimated to be $2 \%$ of the CCS values appearing in Table 1, as it is usually done with this apparatus. ${ }^{[36]}$

All theoretical collision cross-section (CCS) values given in Table 1 of the manuscript have been calculated thanks to simulations carried out with the IMOS software. ${ }^{[28,37]}$ Briefly, the mobility of the ion through a nitrogen gas is calculated by approximating the momentum transfer of gas molecules as their trajectory is bent by the action of an induced dipole. The trajectory method has been used for the simulation of $3.10^{5} \mathrm{~N}_{2}$ molecules with Maxwell-Boltzmann velocity and incoming angle distributions (Pressure $=100 \mathrm{~Pa}$; polarizability $=1.7 \AA^{3}$; radius $=1.5 \AA$; temperature $=298 \mathrm{~K}$ ) colliding with a molecular ion of given 3D structure through a Lennard-Jones interaction potential. After collision, the gas molecules are re-emitted with the mean of the incoming velocities taken from a skewed Maxwell distribution at $298 \mathrm{~K}$. Three perpendicular directions are chosen and the average of the three mobility value is taken to calculate the CCS thanks to the following equation:

$$
\Omega=\frac{3 z e}{4 \rho_{\text {gas }} Z_{p}} \sqrt{\frac{\pi m_{\text {red }}}{8 k T}}
$$

where $z$ is the net charge of the molecular ion, $m_{\text {red }}$ the reduced mass of nitrogen and the molecular ion, $\rho_{\text {gas }}$ the gas mass density and $Z_{p}$ the ion mobility. The accuracy of the simulation has been checked with a rigid molecular ion of known structure: the $\mathrm{C}_{60} 0^{+}$fullerene. Its calculated CCS is $214.3 \AA^{2}$, whereas it has been measured to be $213.1 \AA^{2}{ }^{[38]}$ Therefore, we conclude that this CCS calculation method has an accuracy of about $1 \%$ : the uncertainties appearing in Table 1 have been calculated this way.

Prior to CCS or DFT calculation of the noncovalent complexes between $\mathrm{KYK}$ and $\mathrm{CE}$, we had to generate a geometrical structure for each species studied in this work. Therefore, replica-exchange molecular dynamics simulations have been performed. This method allows an efficient sampling of the potential energy surface of a molecular system, in order to find the structure of the lowest-energy conformation. We have used the AMBER99 force field and 30 replicas were sampled from 10 to $600 \mathrm{~K}$ with a geometric progression. Each replica was propagated for 20 ps for thermalisation to occur, and then for an additional $2 \mathrm{~ns}$ with a $1 \mathrm{fs}$ time step. For thermal equilibrium, we used a Berendsen thermostat with a $0.1 \mathrm{ps}^{-1}$ coupling constant. Exchange between neighboring replicas was attempted every 100 fs. For each replica, a snapshot was taken every $40 \mathrm{ps}$ and all geometries obtained were further minimized in energy with the AMBER99 force field. The lowest-energy conformer was chosen for CCS calculation.

DFT quantum-chemical calculations have been performed at $0 \mathrm{~K}$ to obtain relative energies of the conformers found by REMD. The M06 functional as well as the $6-31+G(d, p)$ and $6-311++G(2 d, 2 p)$ basis sets have been chosen and single-point energy calculations carried out in the ground state of the studied species. To test the hypothesis of multiplyprotonated KYK-CE complexes containing protonated CE, we have performed geometry optimization thanks to minimization of the potential energy at the M06/6-31+G(d,p) level. Initial geometries were obtained from the lowest-energy structures of $[\mathrm{KYK}+2 \mathrm{H}+\mathrm{CE}]^{2+}$ and $[\mathrm{KYK}+3 \mathrm{H}+\mathrm{CE}]^{3+}$ found by REMD simulations (see above), by transferring the proton of the $\mathrm{R}-\mathrm{NH}_{3}{ }^{+}$group bound to $\mathrm{CE}$ to one of the six $\mathrm{O}$ atoms of $\mathrm{CE}$. Whatever the $\mathrm{O}$, the proton was found to be transferred back to $\mathrm{R}$ $\mathrm{NH}_{2}$ after geometry optimization. If the $\mathrm{O}-\mathrm{H}$ distance is frozen during optimization, the conformers found for $[\mathrm{KYK}+2 \mathrm{H}]^{2+}[\mathrm{CE}+\mathrm{H}]^{+}$are $100-130$ $\mathrm{kJ} / \mathrm{mol}$ higher than the initial structures in potential energy. REMD simulations have also been carried out for $[\mathrm{KYK}+\mathrm{H}]+[\mathrm{CE}+\mathrm{H}]^{+}$and $[\mathrm{KYK}+2 \mathrm{H}]^{2+}[\mathrm{CE}+\mathrm{H}]^{+}$, and lead to dissociation of the complex with charge separation, even for $300 \mathrm{~K}$ as maximum temperature. Finally, REMD simulations for $\mathrm{KYK}[\mathrm{CE}+\mathrm{H}]^{+}$allowed obtaining initial structures where protonated CE was not bound to lysine side-chains or the $\mathrm{N}$ terminus, and we could then add two protons to KYK to create the additional conformers of Table S1.

\section{Acknowledgements}

The "Conseil Régional de Normandie" is acknowledged for a PhD funding (\#15P01339), and CNRS for funding through the GDR EMIE. Support for instrument access was provided through the National FT-ICR network (FR 3624 CNRS) for FT-ICR measurement and through the Ile-de-France DIM Analytics regional funding for TWIMS measurements.

Keywords: 18-crown-6-ether • peptides $\cdot$ mass spectrometry • ion mobility spectrometry $\cdot$ electron transfer/capture 
[1] J. L. Casas-Hinestroza, M. Bueno, E. Ibáñez, A. Cifuentes, Analytica Chimica Acta 2019, 1081, 32-50.

[2] K. Pagel, S.-J. Hyung, B. T. Ruotolo, C. V. Robinson, Analytical Chemistry 2010, 82, 5363-5372.

[3] S. Warnke, G. von Helden, K. Pagel, Journal of the American Chemical Society 2013, 135, 1177-1180.

[4] H. Metwally, L. Konermann, Analytical Chemistry 2018, 90, 41264134.

[5] B. C. Bohrer, D. E. Clemmer, Analytical Chemistry 2011, 83, 53775385.

[6] S. M. Dixit, D. A. Polasky, B. T. Ruotolo, Current Opinion in Chemical Biology 2018, 42, 93-100.

[7] H. J. Cooper, K. Hakansson, A. G. Marshall, Mass Spectrometry Reviews 2005, 24, 201-222.

[8] F. Lermyte, D. Valkenborg, J. A. Loo, F. Sobott, Mass Spectrometry Reviews 2018, 37, 750-771.

[9] F. Tureček, R. R. Julian, Chemical Reviews 2013, 113, 6691-6733.

[10] J. S. Prell, J. T. O'Brien, A. I. S. Holm, R. D. Leib, W. A. Donald, E. R. Williams, Journal of the American Chemical Society 2008, 130, 12680-12689.

[11] A. I. S. Holm, P. Hvelplund, U. Kadhane, M. K. Larsen, B. Liu, S. B. Nielsen, S. Panja, J. M. Pedersen, T. Skrydstrup, K. Stochkel, E. R. Williams, E. S. Worm, The Journal of Physical Chemistry A 2007, 111, 9641-9643.

[12] S. Maclot, J. Rangama, S. B. Nielsen, J.-C. Poully, International Journal of Mass Spectrometry 2013, 337, 1-11.

[13] A. Marek, C. J. Shaffer, R. Pepin, K. Slovakova, K. J. Laszlo, M. F. Bush, F. Turecek, Journal of the American Society for Mass Spectrometry 2015, 26, 415-431.

[14] Y. Qi, D. A. Volmer, Rapid Communications in Mass Spectrometry 2015, 29, 2316-2318.

[15] E. Viglino, C. K. Lai, X. Mu, I. K. Chu, F. Turecek, Journal of the American Society for Mass Spectrometry 2016, 27, 1454-1467.

[16] H. T. H. Nguyen, C. J. Shaffer, R. Pepin, F. Turecek, Journal of Physical Chemistry Letters 2015, 6, 4722-4727.

[17] C. J. Shaffer, R. Pepin, F. Tureček, Journal of Mass Spectrometry 2015, 50, 1438-1442.

[18] Y. Chen, M. T. Rodgers, Journal of the American Chemical Society 2012, 134, 2313-2324.

[19] B. Paizs, S. Suhai, Mass Spectrometry Reviews 2005, 24, 508-548.

[20] G. van der Rest, R. Hui, G. Frison, J. Chamot-Rooke, Journal of the American Society for Mass Spectrometry 2011, 22, 1631-1644.

[21] S. Maleknia, J. Brodbelt, Journal of the American Chemical Society 1993, 115, 2837-2843.

[22] C. Hao, F. Tureček, Journal of the American Society for Mass Spectrometry 2009, 20, 639-651.

[23] V. Riffet, D. Jacquemin, G. Frison, International Journal of Mass Spectrometry 2015, 390, 28-38.

[24] R. Pepin, F. Tureček, J. Phys. Chem. B 2015, 119, 2818-2826.

[25] W. A. Donald, R. D. Leib, J. T. O'Brien, A. I. S. Holm, E. R. Williams, Proceedings of the National Academy of Sciences of the United States of America 2008, 105, 18102-18107.

[26] C. Yao, F. Tureček, Phys. Chem. Chem. Phys. 2005, 7, 912-920.

[27] Z. Homayoon, S. Pratihar, E. Dratz, R. Snider, R. Spezia, G. L. Barnes, V. Macaluso, A. M. Somer, W. L. Hase, Journal of Physical Chemistry A 2016, 120, 8211-8227.

[28] C. Larriba, C. J. Hogan, The Journal of Physical Chemistry A 2013, 117, 3887-3901.

[29] J. S. Prell, J. T. O'Brien, J. D. Steill, J. Oomens, E. R. Williams, Journal of the American Chemical Society 2009, 131, 11442-11449.

[30] R. Wu, T. B. McMahon, Angewandte Chemie-International Edition 2007, 46, 3668-3671.

[31] S.-W. Lee, H.-N. Lee, H. S. Kim, J. L. Beauchamp, J. Am. Chem. Soc 1998, 120, 5800-5805.

[32] H. J. Cooper, R. R. Hudgins, K. Hakansson, A. G. Marshall, Journal of the American Society for Mass Spectrometry 2002, 13, 241-249.

[33] D. P. Weimann, H. D. F. Winkler, J. A. Falenski, B. Koksch, C. A. Schalley, Nature Chemistry 2009, 1, 573-577.

[34] H. D. F. Winkler, D. P. Weimann, A. Springer, C. A. Schalley, Angewandte Chemie International Edition 2009, 48, 7246-7250.

[35] F. Turecek, E. A. Syrstad, Journal of the American Chemical Society 2003, 125, 3353-3369.

[36] G. Van der Rest, F. Halgand, J. Am. Soc. Mass Spectrom. 2017, 28, 2519-2522.

[37] C. Larriba, C. J. Hogan, Journal of Computational Physics 2013, 251, 344-363.

[38] I. Campuzano, M. F. Bush, C. V. Robinson, C. Beaumont, K. Richardson, H. Kim, H. I. Kim, Anal. Chem. 2012, 84, 1026-1033. 


\section{Entry for the Table of Contents}

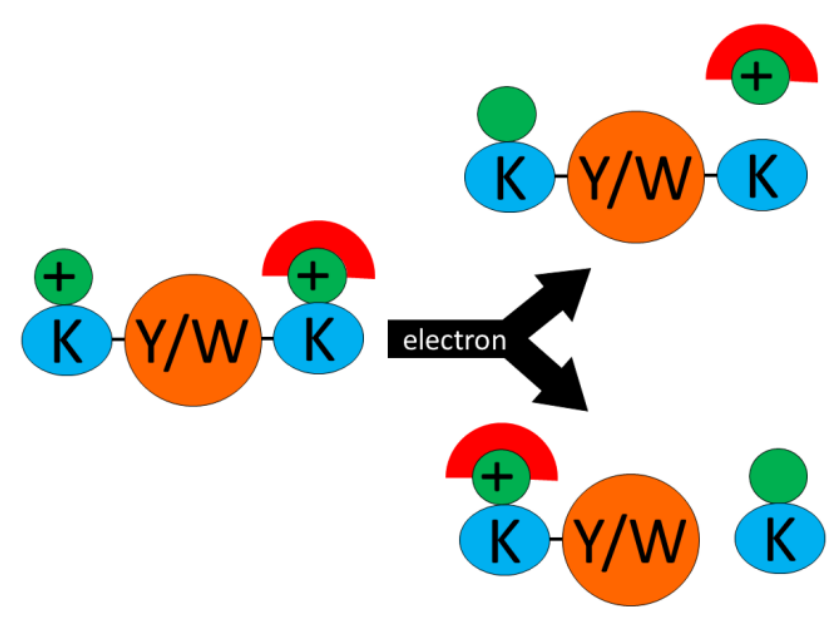

In contrast to what has been widely assumed up to now, we show that 18-crown-6-ether can be involved in chemical processes triggered by activation of their noncovalent complexes with protonated peptides by collisions in argon or electron capture/transfer. Furthermore, we demonstrate that CE can change binding site after electron transfer. We also propose detailed mechanisms for these processes. 